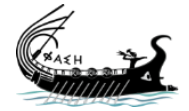

journal.phaselis.org
PHAS LLIS

Issue V (2019)
Disiplinlerarası Akdeniz Araştırmaları Dergisi

Journal of Interdisciplinary Mediterranean Studies

\section{Phaselis Kenti Kıyısında Lesepsiyan Bir Opisthobranch (Plocamopherus ocellatus Rüppell \& Leuckart, 1828)}

\author{
A Lesepsiyan Opisthobranch (Plocamopherus ocellatus \\ Rüppell \& Leuckart, 1828) in the Shore of Phaselis Ancient City
}

\section{Mehmet GÖKOĞLU}

(D) https://orcid.org/0000-0001-9723-8581

\section{Serkan TEKER}

(D) https://orcid.org/0000-0002-3453-6415

Jale KORUN

(D) https://orcid.org/0000-0002-1930-9978

\section{Kemal GÖKOĞLU}

(D) https://orcid.org/0000-0002-2944-7768 open 2 access journals ACCESS JOURNALS

The entire contents of this journal, Phaselis: Journal of Interdisciplinary Mediterranean Studies, is open to users and it is an 'open access' journal. Users are able to read the full texts, to download, to copy, print and distribute without obtaining the permission of the editor and author(s). However, all references to the articles published in the e-journal Phaselis are to indicate through reference the source of the citation from this journal.

Phaselis: Journal of Interdisciplinary Mediterranean Studies is a peer-reviewed journal and the articles which have had their peer reviewing process completed will be published on the web-site (journal.phaselis.org) in the year of the journal's issue (e.g. Issue IV: JanuaryDecember 2018). At the end of December 2018 the year's issue is completed and Issue V: January-December 2019 will begin.

Responsibility for the articles published in this journal remains with the authors.

Citation M. Gökoğlu, S. Teker, J. Korun, K. Gökoğlu "Phaselis Kenti Kıyısında Lesepsiyan Bir Opisthobranch (Plocamopherus ocellatus Rüppell \& Leuckart, 1828". Phaselis V (2019) 125-128. http://dx.doi.org/10.18367/Pha.19006

Received Date: 07.02.2019 | Acceptance Date: 22.03.2019

Online Publication Date: 05.04.2019

Editing

Phaselis Research Project

www.phaselis.org 


\title{
Phaselis Kenti Kıyısında Lesepsiyan Bir Opisthobranch (Plocamopherus ocellatus Rüppell \& Leuckart, 1828)
}

\author{
A Lesepsiyan Opisthobranch (Plocamopherus ocellatus Rüppell \& Leuckart, 1828) \\ in the Shore of Phaselis Ancient City
}

\author{
Mehmet GÖKOĞLU* - Serkan TEKER ${ }^{* *}$ - Jale KORUN ${ }^{* * *}$ - Kemal GÖKOĞLU ${ }^{* * * *}$
}

Öz: İndo-pasifik kökenli bir nudibranch Plocamopherus ocellatus, Akdeniz'de farklı birkaç bölgede daha önce rapor edilmiştir. P. ocellatus'un Türkiye kıyılarından ilk kaydı Kaş'ta verilmiştir. Daha sonra bu tür İskenderun Körfezi'nde kayda geçmiştir. Phaselis Alacasu Koyu'nda, algler üzerine yapılan bir bilimsel çalışma esnasında yapılan scuba dalışında, P. ocellatus belgelenmiştir. Bu örnek doğal ortamından alınarak bir kovaya konulmuş, fotoğrafı çekildikten sonra tekrar doğaya salıverilmiştir. Bu çalışma $P$. ocellatus'un Türkiye Suları́ndaki üçüncü kaydıdır.

Anahtar sözcükler: Phaselis, Plocamopherus ocellatus, Lesepsiyan, Nudibranch

Abstract: The nudibranch Plocamopherus ocellatus, originated from indo-pacific, has been reported in several regions of the Mediterranean Sea. First record of $P$. ocellatus in the coasts of Turkey was reported from Kaş. Later, this species was recorded from the Gulf of İskenderun. In a scientific study on algae in the Phaselis Alacasu Bay, P. ocellatus was seen during scuba diving. The species was taken into a bucket from its natural habitat and then released back to nature after its photograph was taken. In this study, third record of $P$. ocellatus was reported in Turkey's waters.

Keywords: Phaselis, Plocamopherus ocellatus, Lessepsian, Nudibranch

Giriş

Plocamopherus ocellatus Rüppell and Leuckart, 1828 Akdeniz ekosistemine sonradan girmiş Indo-pasifik kökenli bir nudibranch türüdür. Şu ana kadar bu tür Akdeniz ekosisteminde sadece birkaç lokasyondan bildirilmiştir ${ }^{1}$. Rothman ve Galil $(2015)^{2}$ bildirdiğine göre Akdeniz'de bu tür ilk kez 1977 yılında İsrail kıyılarında 50 m derinlikte çamurlu bir zeminde görülmüştür. Bu tarihten sonra türün bir örneği Kaş’ta (1998)³ kayalıklar arasında 8-10 m derinlikler arasından fotoğraf-

* Prof. Dr., Akdeniz Üniversitesi, Su Ürünleri Fakültesi, Su Ürünleri Yetiştiriciliği Anabilim Dalı, Antalya, gokoglu@akdeniz.edu.tr | (D) https://orcid.org/0000-0001-9723-8581

** Ph.D., Akdeniz Üniversitesi, Su Ürünleri Fakültesi, Su Ürünleri Mühendisliği Anabilim Dalı, Antalya. srkntkr@gmail.com | (D) https://orcid.org/0000-0002-3453-6415

** Prof. Dr., Akdeniz Üniversitesi, Su Ürünleri Fakültesi, Su Ürünleri Yetiştiriciliği Anabilim Dalı, Antalya, jalekorun@akdeniz.edu.tr | D https://orcid.org/0000-0002-1930-9978

*** MA., Süleyman Demirel Üniversitesi, Su Ürünleri Fakültesi, Su Ürünleri Avcllık Anabilim Dalı, Isparta, scbant07@gmail.com | (D) https://orcid.org/0000-0002-2944-7768

1 Çevik-Cavas 2012.

Rothman - Galil 2015.

3 Rudman 2002. 
lanmıştır ${ }^{4}$ (Rudman 2002; Yokeş ve Rudman 2004). Yine Rothman ve Galil (2015)5'in bildirdiğine göre P. ocellatus 2000, 2002 ve 2003 yıllarında Lübnan kıyılarından da bildirilmiştir.

Çevik ve Cavaş (2012) ${ }^{6}$ bu türü 15 Aralık 2011 tarihinde İskenderun Körfezi'nin kayalık bir bölgesinde $4 \mathrm{~m}$ derinlikte tespit etmişlerdir. Kleitou vd., (2015) ${ }^{7}$ Mayıs 2015 tarihinde $P$. ocellatus'u Magosa'nın Protaras bölgesinde 25 m derinlikte bir batığa scuba dalışı yaparken tespit etmişlerdir. Bu araştırıcılar Güney Kıbrıs'ta yapay resif olarak batırılan başka batıklarda da bu türü tespit etmişler ve yapay resiflerin bu tür için uygun habitatlar oluşturduğu kanısına varmışlardır.

Çevik ve Cavaş (2012) ${ }^{8}$ iskenderun Körfezi'nde yaptıkları çalışmada P. ocellatus'un 8 bireyini tespit etmişlerdir. Yine bu çalışma sırasında türün yumurta kümelerine de rastlamışlardır. Yaptıkları bu çalışmada araştırıcılar, türün Akdeniz'de farklı lokasyonlarda görülmesi ve yumurta kümelerinin varlığına dayanarak bu canlının Akdeniz ekosisteme başarıyla yerleştiği kanısına varmışlardır. Yine araştırıcılar P. ocellatus'un İskenderun Körfezi'ne girmesinin Süveyş Kanalı yoluyla veya gemilerin balast sularıyla taşınmış olabileceği bildirmişlerdir.

Phaselis kenti çevresinde deniz algleriyle ilgili yaptığımız bir araştırma sırasında scuba dalışı yapılmış ve daha önce Antalya Körfezi'nde görmediğimiz bir nudibranch türüne rastlanılmıştır. Bu türün belirlenmesi ve Phaselis kentini sualtı biyolojik çeşitliliğine dâhil edilmesi, bu çalışmanın amacını oluşturmaktadır.

\section{Materyal ve Metod}

Phaselis Antik Kenti, Alacasu Koyu kayalık bölgesinin 6-7 m derinliklerinde yaptığımız alg araştırmaları esnasında, 36²3 '5.32"K; 30³3'48.05"D koordinatlarına scuba dalışı yapılmıştır. Bu dalışlar sırasında kayalık bölgede farklı bir nudibranch türüne rastlanılmıştır. Bu tür bulunduğu bölgeden bir kova içerisine alınmış ve teknede fotoğrafı çekilmiştir. Fotoğraf çekiminden sonra bu nudibranch tekrar doğal ortamına bırakılmıştır. Daha sonra bu Nudibranch'ın, Rudman (2002) $)^{9}$; Çevik ve Cavaş (2012) ${ }^{10}$; Rothman ve Galil (2015) ${ }^{11^{\prime}}$ e göre fotoğraflardan tür teşhisi yapılmıştır.

\section{Bulgular}

Phaselis Phaselis Antik Kenti, Alacasu Koyu kayalık bölgesi 6-7 m derinliklerde görülen Nudibranch türü, Polyceridae familyası, Plocamopherus genusu ait Plocamopherus ocellatus olarak teşhis edilmiştir (Fig 1). Bu türün boyu yaklaşık $11 \mathrm{~cm}$ olarak belirlenmiştir. Vücut rengi koyu kahverengidir. Vücut üzerinde portakal renginde yuvarlak benekler bulunmaktadır. Ayrıca dorsal bölgede yüzgeç benzeri bir yapı yer almaktadır.

\section{Tartışma ve Sonuç}

Araştırmamızda Phaselis Antik Kenti, Alacasu koyunda tespit ettiğimiz Nudibranch türü Plocamopherus ocellatus'tur. Kızıldeniz orijinli olan bu tür Akdeniz ekosistemine sonradan dahil olmuştur. Süveyş Kanalı, İndo-pasifik orijinli birçok canlının Akdeniz’e geçiş yolunu oluşturmakta-

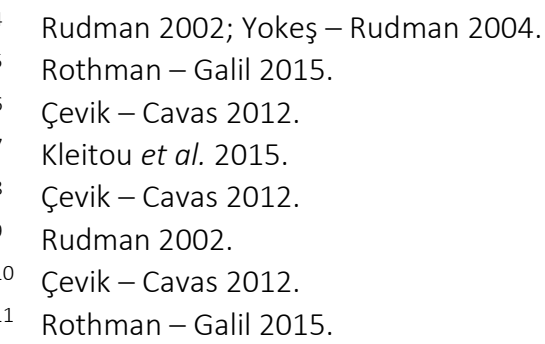


dır. Bu kanalı kullanarak Akdeniz’e göç eden türlere Lesepsiyan türler denilmektedir ${ }^{12}$.

Plocamopherus ocellatus çok nadir görülen bir Nudibranch türüdür ${ }^{13}$. Rothman ve Galil $(2015)^{14 \prime}$ nın bildirdiğine göre, son yıllarda bu tür Kızıldeniz'in yanı sıra Arap Körfezi'nde de rastlanılmıştır.

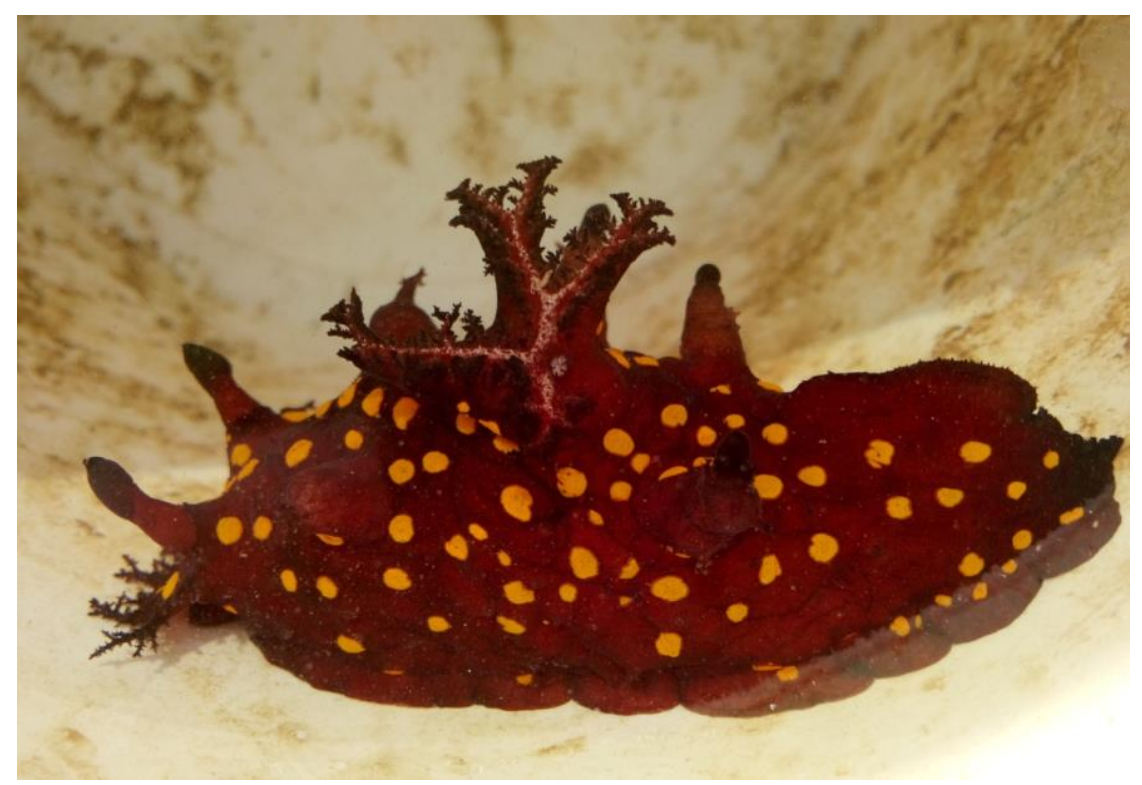

Fig. 1. Plocamopherus ocellatus

Akdeniz ekosisteminde ise bu türe ilk kez 1977 yılında İsrail'in Nitzanim kıyısında rastlanılmıştır ${ }^{15}$. Daha sonra P. ocellatus'un Akdeniz' de bir kaç lokasyondan daha bildirimi yapılmıştır.

Türkiye kıyılarından bu tür ilk kez Kaş'tan ${ }^{16}$ bildirilmiştir. Daha sonra türün bildirimi İskenderun Körfezi'nden de yapılmışıır ${ }^{17}$. Bu araştırıcılar İskenderun Körfezi'nde yaptıkları çalışma sırasında türün yumurta kümelerine de rastlamışlardır. Bu bulguları yorumlayan araştırıcılar türün Akdeniz ekosistemine adaptasyonunu başarıyla sağladığını bildirmişlerdir.

Bu araştırma Phaselis Antik Kenti çevresinde yapılmıştır. Phaselis Antik Kenti çevresinde bu çalışmayla $P$. ocellatus'un varlığının bildirimi, Türkiye kıyılarından üçüncü lokasyon kaydını oluşturmaktadır. Bu kayıtla Phaselis Antik Kenti biyolojik çeşitliliğine lesepsiyan bir tür daha ilave edilmiştir.

Phaselis halkı, Kızıldeniz orijinli olan bu türü antikçağda, büyük bir ihtimalle hiç görmemiş ve bilmemiştir.

Golani 1998.

13 Çevik - Cavas 2012.

14 Rothman - Galil 2015.

15 Rothman - Galil 2015. 
Golani 2005

Kleitou et al. 2015

Rothman - Galil 2015

Rudman 2002

Yokeş - Rudman 2004

\section{BİBLIYOGRAFYA}

D. Golani, Distribution of Lessepsian migrant fish in the Mediterranean, Italian Journal of Zoology, 65/1 (1998) 95-99. http://dx.doi.org/10.1080/11250009809386801

P. Kleitou, F. Crocetta, D. Poursanidis, , Web contribution to native and alien species distribution: four new records from Cyprus. Medit. Mar. Sci., 16/3 (2015) 682-702.

S. Rothman, B. S. Galil, Not so rare: Plocampherus ocellatus (Nudibranchia, Polyceridae) in the Eastern Mediterranean. Marine Biodiversity Records 8 (2015) e144. http://dx.doi.org/10.1017/s1755267215001207

W. B. Rudman, Comment on Plocamopherus ocellatus from Turkey by Erwin Koehler. [Message in] Sea Slug Forum. (2002) Sydney: Australian Museum. Available at: www.seaslugforum.net/find/8516 (accessed 04 Feb. 2019).

B. Yokes, - W. B. Rudman, "Lessepsian opisthobranchs from southwestern coast of Turkey; five new records for Mediterranean". Rapp Réunions Comm Int Explor Sci Mer. Méditerr 37 (2004) 557. 